\title{
Role of the Homeodomain Transcription Factor Bapx1 in Mouse Distal Stomach Development
}

\author{
MICHAEL P. VERZI, ${ }^{\star}$ MONIQUE N. STANFEL, ${ }^{\ddagger}$ KELVIN A. MOSES, ${ }^{\ddagger}$ BYEONG-MOO KIM, ${ }^{\star}$ YAN ZHANG, ${ }^{\S}$

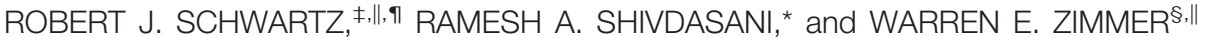 \\ *Department of Medical Oncology, Dana-Farber Cancer Institute and Department of Medicine, Harvard Medical School, Boston, Massachusetts; ${ }^{\ddagger}$ Department of \\ Molecular and Cellular Biology, Baylor College of Medicine, Houston, Texas; ${ }^{\circledR}$ Department of Systems Biology and Translational Medicine and "Center for \\ Environmental and Rural Health, Texas A\&M University, College of Medicine, College Station, Texas; and "Institute of Biosciences and Technology, Texas A\&M \\ University Health Science Center, Houston, Texas
}

Background \& Aims: Expansion and patterning of the endoderm generate a highly ordered, multiorgan digestive system in vertebrate animals. Among distal foregut derivatives, the gastric corpus, antrum, pylorus, and duodenum are distinct structures with sharp boundaries. Some homeodomain transcription factors expressed in gut mesenchyme convey positional information required for anterior-posterior patterning of the digestive tract. Barx1, in particular, controls stomach differentiation and morphogenesis. The Nirenberg and Kim homeobox gene Bapx1 (Nkx3-2) has an established role in skeletal development, but its function in the mammalian gut is less clear. Methods: We generated a Bapx $1^{\text {Cre }}$ knock-in allele to fate map Bapx1-expressing cells and evaluate its function in gastrointestinal development. Results: Bapx1-expressing cells populate the gut mesenchyme with a rostral boundary in the hindstomach near the junction of the gastric corpus and antrum. Smooth muscle differentiation and distribution of early regional markers are ostensibly normal in Bap $x 1^{\mathrm{Cre} / \mathrm{Cre}}$ gut, but there are distinctive morphologic abnormalities near this rostral Bapx1 domain: the antral segment of the stomach is markedly shortened, and the pyloric constriction is lost. Comparison of expression domains and examination of stomach phenotypes in single and compound Barx1 and Bapx1 mutant mice suggests a hierarchy between these 2 factors; Bapx1 expression is lost in the absence of Barx1. Conclusions: This study reveals the nonredundant requirement for Bapx1 in distal stomach development, places it within a Barx1-dependent pathway, and illustrates the pervasive influence of gut mesenchyme homeobox genes on endoderm differentiation and digestive organogenesis.

$\mathrm{M}$ echanisms responsible for organizing the mammalian stomach into fundus, corpus, and antral-pyloric segments are poorly understood. Corpus epithelium typically carries numerous oxyntic and zymogenic cells that produce acid and digestive enzymes, respectively. ${ }^{1}$ The distal stomach, which encompasses the antrum and pylorus, lacks these cell lineages but is marked in mouse and man by presence of endocrine cells that secrete gastrin and mucous cells that produce mucin $6 .{ }^{1}$ Muscle cells in the outer pylorus create a sphincter that controls passage of food into the duodenum.

The digestive tract differentiates in response to signals from adjacent mesenchyme. ${ }^{2}$ Expression of homeobox genes is often segmental along the anterior-posterior axis of the developing gut and may be especially important in relaying rostro-caudal position. ${ }^{3}$ Clustered Hox genes, for example, are expressed in the gut in overlapping domains, reminiscent of patterns observed along the skeletal axis ${ }^{4,5}$; they are implicated in regional identity and in formation of intestinal sphincters and the cecum. ${ }^{6-10}$ Homeodomain proteins participate in mesoderm-endoderm signaling.

The homeobox gene Barx1 is confined to embryonic stomach mesenchyme and is required for proper stomach development. ${ }^{10-13}$ In its absence, the stomach is markedly small, abnormally shaped, lacks a pyloric constriction, shows mixing of cells from different segments, and carries intestinal villi distally. ${ }^{11,12}$ Some homeobox genes regulate fibroblast growth factor expression in the hindgut, ${ }^{10}$ and overexpression of NKX2.5 in chick embryos inhibits $W n t 5 a$ and Bmp4 expression during formation of the hindstomach (gizzard) and pylorus ${ }^{14,15}$; Barx 1 acts in part by limiting the duration of Wnt signaling in early stomach development. ${ }^{11,12}$ Many other factors that regulate genetic and tissue interactions in stomach development remain unknown.

The homeodomain of mammalian Nkx3-2 (Bapx1) shares $\sim 87 \%$ identity with Drosophila BAGPIPE, a NK2 subfamily member that specifies gut smooth muscle in flies. ${ }^{16}$ Viral misexpression studies in the chicken suggest that Bapx1 functions in development of the gizzard, a muscular, keratinized structure in the posterior stomach. ${ }^{15}$ In mouse embryos, Bapx 1 messenger RNA (mRNA) appears first in lateral plate mesoderm, adjacent to gut endoderm, around embryonic day (E) 8.5. ${ }^{17}$ Bapx 1 knock- 
out mice were therefore predicted to have gut musculature defects, but the intestine in 3 separate mutant lines is largely intact, ${ }^{18-20}$ and investigation has centered on Bapx1's role in spleen and skeletal development. One group commented on abnormal gastro-duodenal morphology ${ }^{20}$ without investigating molecular details. Although the nature and possible reasons for the defect are unknown, Bapx1 is cited as being required to generate pyloric sphincter muscle. ${ }^{21}$

We created a targeted mouse line that marks Bapx1expressing cells and eliminates gene activity. Here, we report that Bapx1 is necessary for proper antral-pyloric morphogenesis and development of antral-type epithelium. We also show that Bapx1 expression in the distal stomach requires Barx1. These studies reveal a focal requirement for $B a p x 1$ in hindstomach organogenesis and outline a transcriptional hierarchy in mammalian stomach development.

\section{Materials and Methods}

\section{Mouse Gene Targeting}

A $\lambda$-phage clone from a $129 / \mathrm{Sv}$ mouse genomic library was provided by Drs. K.-I. Yoshiura and J. Murray, University of Iowa (Iowa City, IA). A 3.6-kilobase (kb) BglII-SacII fragment containing $5^{\prime}$ flanking sequences and the first 46 codons of Bapx1 exon 1 served as the 5'homology arm; a 1.6-kb SmaI fragment containing codon 112 through the end of exon 2 served as the $3^{\prime}$-homology arm. A PGK-Neo ${ }^{R}$ cassette and Cre recombinase complementary DNA (cDNA) were inserted in frame with Bapx1 coding sequence at the SacII restriction site (Figure 1A). The construct was electroporated into AB2.2 embryonic stem cells. Two targeted cell lines were used to produce chimeras and Bap $x 1^{+/ C r e}$ mice. For Southern genotyping, the probe was a $\left[\alpha^{-32} \mathrm{P}\right]$ dCTP-labeled BglII-SacI fragment from the $3^{\prime}$ segment of the gene, which identifies $5-\mathrm{kb}$ and $7.5-\mathrm{kb}$ bands for wild-type and Cre knock-in alleles, respectively (Figure $1 B$ ). To demonstrate correct targeting at the $5^{\prime}$ end, we used primers complementary to the Cre insert (CRE3': GCCGCATAACCAGTGAAACAGCATTGC) and to genomic DNA $\sim 4.5-\mathrm{kb} 5^{\prime}$ to the Bapx 1 gene (GTTATGAGTGACAGCCTGGGACG) to amplify a 5.7-kb DNA fragment in the targeted allele (Supplementary Figure 1). Identity of this fragment was confirmed by B $g l \mathrm{II} / \mathrm{ClaI}$ digestion and sequence analysis using internal primers GGTTTCAAAATGAGGCTC and CATGTATGAATGTGTGGAACCTGG. For subsequent genotyping, we used CRE3' along with CTCGTTCTCTTCGCTCAGGGCTGAG and CCAGGCGATCCTCAACAAGAAGAGGG in a coupled polymerase chain reaction (PCR) reaction with a $56^{\circ} \mathrm{C}$ annealing step (Figure 1C). Bapx1 targeted mice were maintained on the C57BL/6 background.
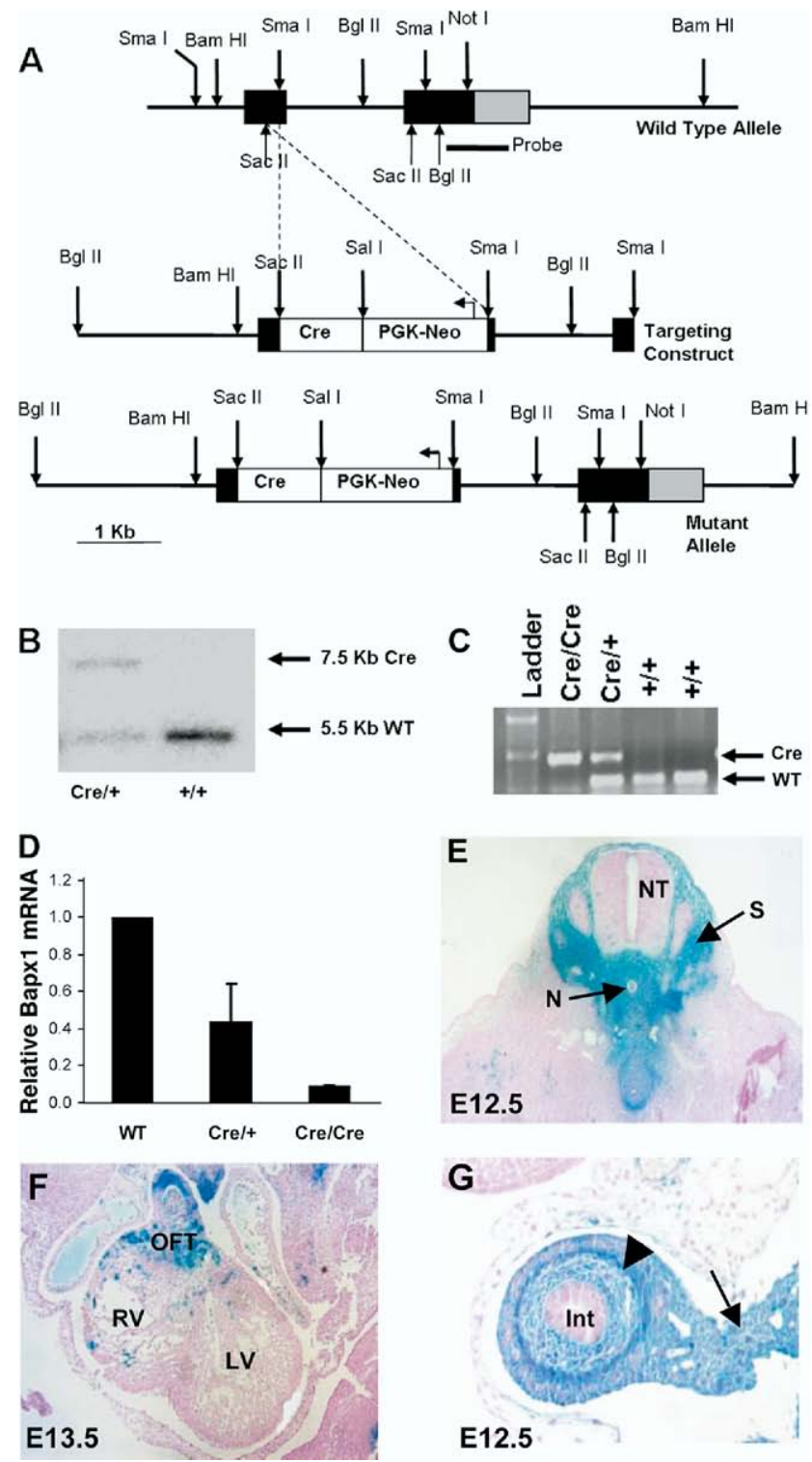

Figure 1. Generation of Bapx $1^{\text {Cre }}$ targeted mice and their application to examine Bapx1 gene expression. (A) Molecular strategy to generate ES cells with Cre recombinase targeted to the first Bapx 1 exon between the Sacll and Smal sites. (B) Mice were genotyped by Southern hybridization using probes corresponding to the $3^{\prime}$ half of exon 2 and part of the $3^{\prime}$ untranslated region. Subsequent generations were genotyped by PCR (C). (D) Confirmation that Bapx1 expression is extinguished in Bap $\times 1$ Cre/Cre mice. qRT-PCR on fetal and newborn tibial RNA, expressing Bapx 1 mRNA content relative to Gapdh mRNA in wild-type (WT, $\mathrm{n}=$ 10), Bapx $1^{\mathrm{Cre} /+}(\mathrm{HET}, \mathrm{n}=14)$, and Bapx $1^{\mathrm{Cre} / \mathrm{Cre}}(\mathrm{KO}, \mathrm{n}=10)$ samples. $(E-G) B a p \times 1^{C r e /+}$ mice were crossed with the ROSA26R reporter strain, and progeny were examined for Cre-expressing cells and their descendants by $\beta$-galactosidase activity. In E12.5 embryos, staining was detected in sites of documented Bapx1 expression or function, including condensing vertebrae $(E)$ and gut mesenchyme (arrowhead) and mesentery (arrow) (G). Staining also appeared in E13.5 cardiac outflow tract $(F)$ and, later, throughout the developing skeleton (see Supplementary Figure 1). OFT, cardiac outflow tract; RV, right ventricle; LV, left ventricle; CC, central canal; NT, neural tube; N, notochord; S, sclerotome. 


\section{Expression Analyses}

$\beta$-galactosidase activity was determined on wholemount preparations using published methods. ${ }^{22}$ For histology, embryos were embedded in paraffin, sectioned at $5 \mu \mathrm{m}$, and stained with H\&E. Bap $\times 1^{\mathrm{Cre} /+}$ and Barx $1^{+/-}$ mice were intercrossed to obtain compound homozygotes. Organs from crosses with Nkx2.5-GFP transgenic mice, described previously, ${ }^{23}$ were visualized under a Leica MZ FLIII fluorescent dissecting microscope.

RNA was reverse transcribed using SuperScript (Invitrogen, Carlsbad, CA). cDNA was detected by PCR using Bapx1 primers agatgtcagccagcgtttc and gcagaggcgagcaggtcggc. Fetal stomach lysates were resolved by SDS-PAGE. Binding of Bapx1 mouse antiserum H00000579-A01 (1:500; Abnova, Taipei, Taiwan) was detected with horseradish peroxidase-conjugated goat antimouse antibody $(\mathrm{Ab})$.

Embryos were fixed overnight in $4 \%$ paraformaldehyde at $4^{\circ} \mathrm{C}$. Eight-micrometer-thick paraffin sections were dried, deparaffinized in xylenes, and rehydrated. For antigen retrieval, slides were immersed in $10 \mathrm{mmol} / \mathrm{L} \mathrm{so-}$ dium citrate, $\mathrm{pH} 6.0$, and treated in a pressure cooker for 2 minutes at 15 psi. Endogenous peroxidase activity was blocked with $3 \% \mathrm{H}_{2} \mathrm{O}_{2}$ in methanol for 15 minutes and nonspecific $\mathrm{Ab}$ binding with $5 \%$ fetal bovine serum for 1 hour at $25^{\circ} \mathrm{C}$. Primary Ab: SM $\alpha$ A (Sigma A2547 [1A4], 1:1000; Sigma-Aldrich, St. Louis, MO), PGP9.5 (1:2500; Chemicon AB1761), H/K-ATPase (D032-3; 1:1000; MBL International Woburn, MA), intrinsic factor $(1: 24,000$; gift from Dr. D. Alpers; Washington University, St. Louis, MO), Pdx1 (1:6000, gift of Dr. C. Wright, Vanderbilt University, Nashville, TN), BMP4 (1:300, Chemicon MAB1049), and Nkx 2.5 (1:200, SC14033; Santa Cruz Biotechnology, Santa Cruz, CA) were applied for 3 hours at $25^{\circ} \mathrm{C}$ or overnight at $4{ }^{\circ} \mathrm{C}$. After treating with antimouse or anti-rabbit IgG (Jackson ImmunoResearch, West Grove, PA) then avidin-biotin complex solution (Vector Laboratories, Burlingame, CA) for 1 hour at $25^{\circ} \mathrm{C}$, color reactions were developed in $0.05 \% 3$, 3'-diaminobenzidine and $0.1 \% \mathrm{H}_{2} \mathrm{O}_{2}$. Slides were counterstained with hematoxylin. Alcian blue staining was by standard methods.

For in situ hybridization, tissues were fixed in $4 \%$ paraformaldehyde (Sigma-Aldrich), dehydrated, embedded in paraffin, and sectioned at $6-\mu \mathrm{m}$ thickness. Deparaffinized, rehydrated sections were treated with Proteinase $\mathrm{K}$ (Roche, Pleasanton, CA) and $0.1 \mathrm{~mol} / \mathrm{L}$ triethanolamine before hybridization with probes generously provided by T. Lufkin (Bapx1), A. McMahon (Ibb), and R. Harvey (Nkx2.5). After overnight hybridization at $63^{\circ} \mathrm{C}$, slides were washed for 2 hours in decreasing concentrations of SSC from $2 \mathrm{X}$ to $0.2 \mathrm{X}$ at $63^{\circ} \mathrm{C}$ then incubated in $5 \%$ serum in phosphate-buffered saline followed by digoxigenin $\mathrm{Ab}$ (1:2000; Roche) at $4^{\circ} \mathrm{C}$ overnight. Slides were equilibrated in $100 \mathrm{mmol} / \mathrm{L} \mathrm{NaCL} ; 100 \mathrm{mmol} / \mathrm{L}$ Tris, $\mathrm{pH}$ 9.5; and $50 \mathrm{mmol} / \mathrm{L} \mathrm{MgCl}_{2}$ and stained (NBT/ BCIP tablets; Roche) for 2- 4 hours.

For expression arrays, RNA was extracted from the distal stomach of E18.5 Bap $x 1^{\mathrm{Cre} / \mathrm{Cre}}$ embryos and wildtype littermates using the RNeasy kit (Qiagen, Valencia, CA). After confirmation of RNA quality, samples were processed and hybridized to Codelink mouse bioarrays (Amersham Biosciences, Piscataway, NJ). Raw data were normalized on a $\log _{2}$ scale and filtered to reduce noise. Differential gene expression and functional gene groupings were analyzed using MatchMiner (http://discover.nci.nih.gov/matchminer/), GoMiner (http://discover.nci.nih.gov/gominer/), and GeneSpring (Agilent Technologies, Santa Clara, CA) software and are deposited in the GEO database (GSE 13935).

\section{Results}

\section{Tracing Bapx1 Expression}

We used homologous recombination to replace Bapx1 at codon 46 (exon 1) with in-frame Cre cDNA (Bapx $1^{\text {Cre }}$, Figure 1A). Two independent mutant lines showed evidence for correct gene targeting (Figure $1 B$ and $1 C$ ) loss of Bapx 1 mRNA (Figure $1 D$ ) and no material effect on expression of the 2 flanking genes (Supplementary Figure 1C). We crossed these mice with ROSA26 reporter mice, in which a floxed translation-stop sequence restricts $L a c Z$ gene expression to Cre-expressing cells and their progeny. ${ }^{24} \beta$-galactosidase ( $\beta$-gal/LacZ) activity first appeared in Bapx $1^{\mathrm{Cre}} ;$ ROSA26R embryos at E9.5 in gut mesoderm and weakly in somites (Figure $2 A$ and $2 B$; data not shown). Between E10.5 and E12.5, $\beta$-gal activity was prominent in the splanchnic mesoderm, somites, calvarium, Meckel's cartilage, and spleen anlage (Figures $1 E, 2 C$ and $1 D$, and Supplementary Figure $2 A-$ $2 G$ ). By E13.5, Bapx1 expression was evident in the cardiac outflow tract (Figure $1 F$ ) and condensing cartilage of the ribs, skull (Supplementary Figure $2 I-2 N$ ), and long bones. Staining in the digestive tract was confined to mesodermal derivatives and excluded from endoderm at all stages (Figures $1 G$ and $2 E$ and $2 F$ ). These findings agree with previous reports of Bapx1's role in developing skeleton and spleen ${ }^{17-20}$ and establish the fidelity of Bapx $1^{\text {Cre }}$ mice to mark Bapx1-expressing cells and elucidate Bapx1 function in other organs.

Definition of gene expression along the long axis of the embryonic stomach is confounded by rotation of the organ from an initial lie parallel to the body's anterior-posterior axis to a final position that is nearly perpendicular. We examined serial embryo sections with the attention required to distinguish the stomach's antero-posterior and radial axes. LacZ expression in Bap $x 1^{\mathrm{Cre} /+}$ embryonic gut initiated in the distal stomach. Staining at E10.5 was intense in the caudal foregut and stomach-intestine junction but absent 

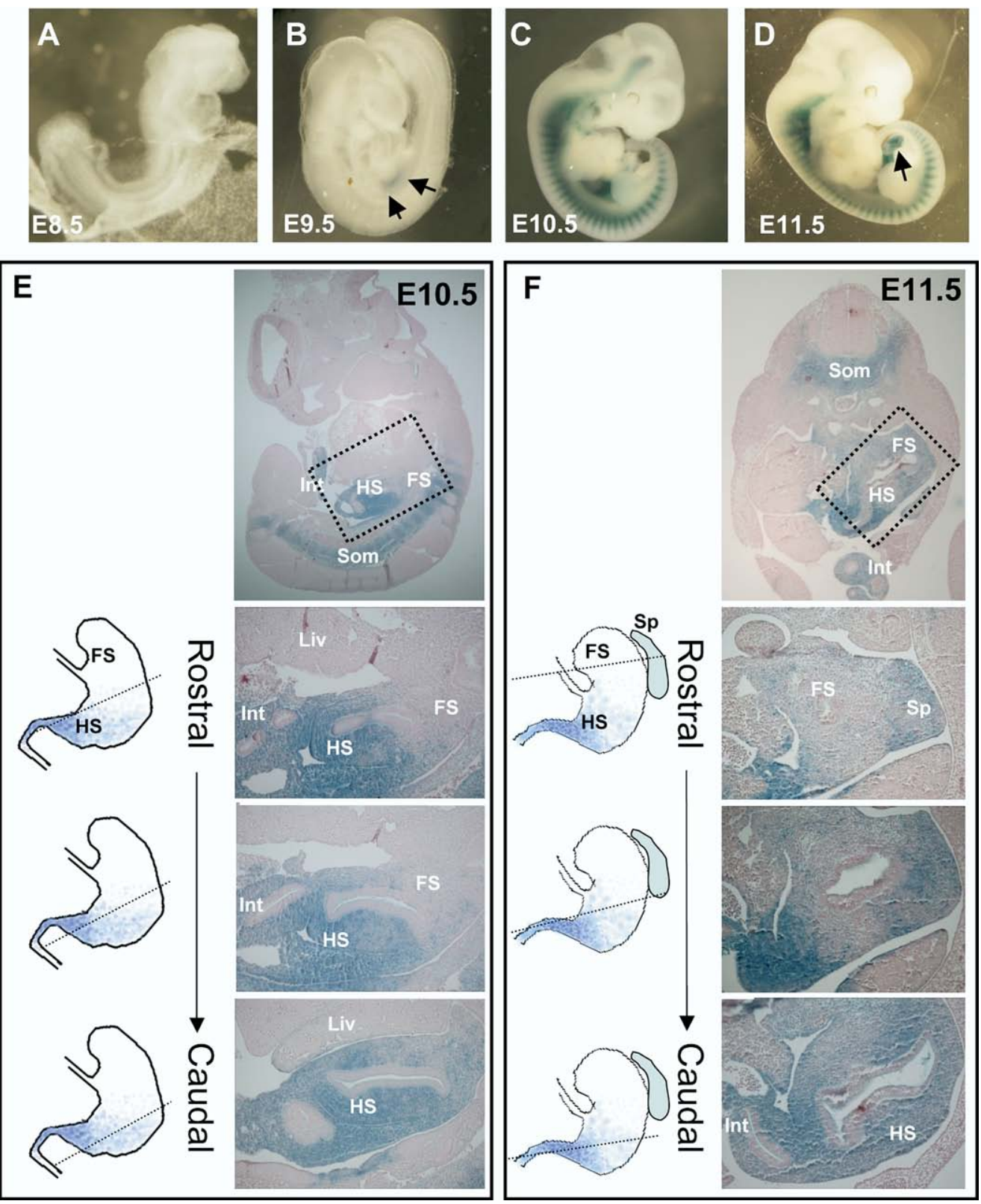

Figure 2. Lineage mapping in Bapx $1^{\text {Cre }}$ mice reveals a rostral boundary of Bapx1 gene expression in embryonic hindstomach. (A-D) Whole-mount LacZ staining of Bapx $1^{\mathrm{Cre} /+} ; \mathrm{ROSA} 26 \mathrm{R}$ embryos identifies Cre-expressing cells and their descendants. Staining is not apparent through E8.5 (A) and first appears near the stomach-intestine boundary by E9.5 ( $B$, arrows). By E10.5, LacZ activity is evident in all anterior somites and in gut and craniofacial mesenchyme $(C)$. Expression is readily apparent in mesenchyme of herniated E11.5 intestine $(D$, arrow). ( $E$ and $F$ ) Microscopic examination exposes a rostral limit of $L a c Z$ activity in the hindstomach at E10.5 $(E)$ and E11.5 (F): intestine (Int) and hindstomach (HS) are stained strongly, whereas forestomach (FS) activity is much reduced or absent. Som, somites; Liv, liver; $\mathrm{Sp}$, spleen. Sections from embryos at each stage are arranged in rostral to caudal sequence from areas corresponding to those outlined by dotted boxes. Rostral sections show minimal LacZ activity in the forestomach compared with the caudal (hindstomach) tissue or spleen (Sp). Schemas for the domain of Bapx1 gene expression in relation to stomach and spleen anatomy are depicted next to each section, with a dotted line indicating the approximate plane of section. from the rostral foregut and stomach (Figure $2 E$, sections from the same embryo in a rostral to caudal series). At E11.5, expression remained evident in the hindstomach but faint or absent in forestomach (Figure $2 F$ ), extended into the full-length of intestine, and included the spleen anlage (Figure $2 F$ ). LacZ staining involved all cells in the full thickness of the mesenchyme (Supplementary Figure 3). In older embryos, $\beta$-gal activity was present in much of the stomach, with a persistent caudal-to-rostral gradient (data not shown).

Early chick embryos express Bapx 1 in the prospective gizzard (posterior stomach) but not the proventriculus (anterior stomach). ${ }^{15}$ Our Cre-based lineage analysis in mice confirmed Bapx1 expression in tissues with known functions and disclosed an anterior boundary previously unappreciated in mammalian stomach. The rostral limit of earliest Bapx1 expression corresponds roughly to the junction between corpus and antrum.

\section{Abnormal Stomach Development in Bapx $1^{\text {Cre }}$ Homozygotes}

Crosses between Bapx $1^{+/ C r e}$ mice yielded null mutants in Mendelian proportions until E18.5 (25.6\% Bap $x 1^{+/+}$, 48\% Bapx $1^{\mathrm{Cre} /+}$, and 26.4\% Bapx $\left.1^{\mathrm{Cr} / \mathrm{Cre}}\right)$. Mutant homozygotes typically died 1 to 3 days after birth, and $\sim 90 \%$ of weanlings were wild-type or heterozygote. Perinatal lethality, similar to that reported with other Bapx1null alleles, ${ }^{17-20}$ likely reflects skeletal malformation (Supplementary Figure $2 O$ and $2 P$ ). The spleen was absent or markedly hypoplastic in Bapx $1^{\mathrm{Cre} / \mathrm{Cre}}$ mice, as judged grossly (Figure $3 B$ ) and by expression of a Nkx2.5- 


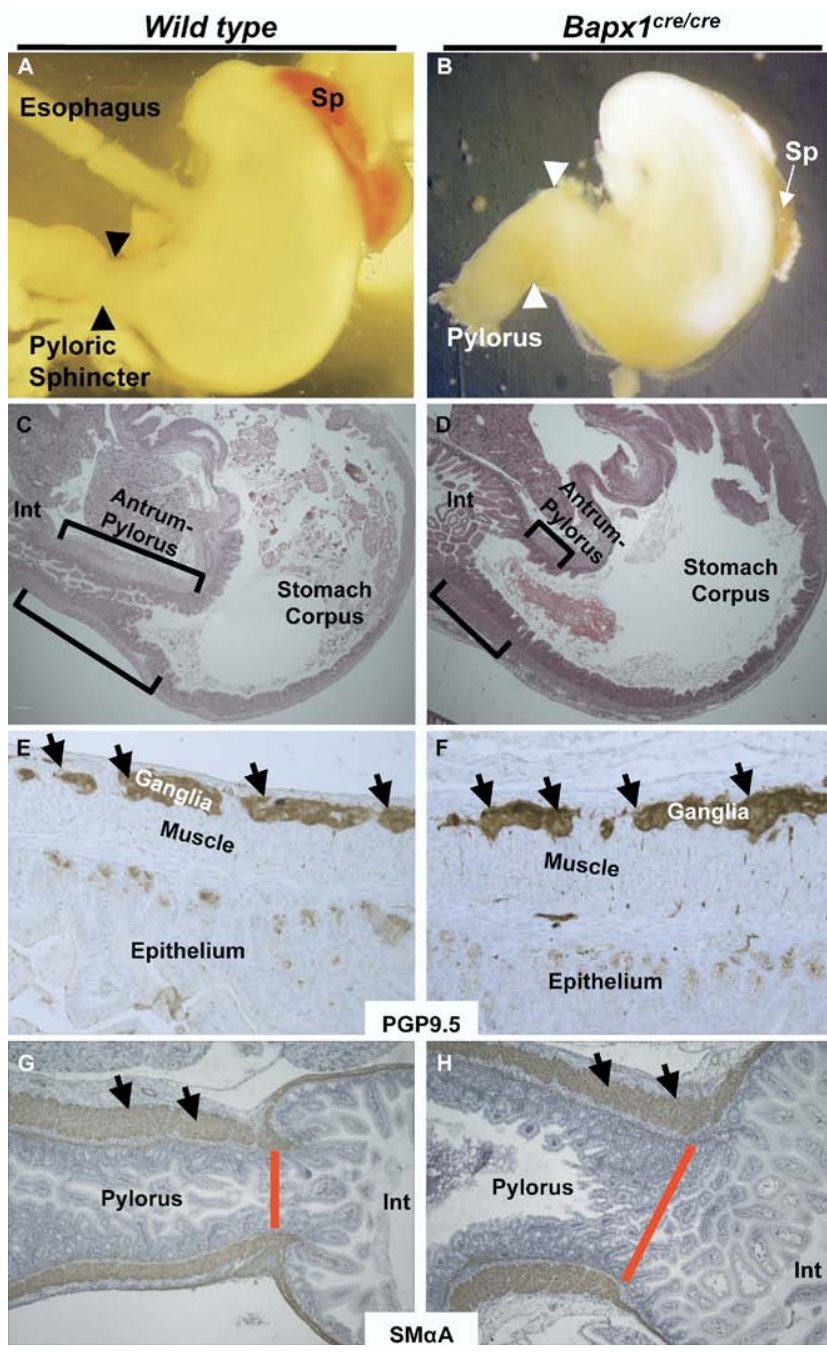

Figure 3. Stomach development in the absence of Bapx1 function. $(A-D)$ Gross and microscopic evidence for hindstomach defects in Bap $1{ }^{\mathrm{Cre} / \mathrm{Cre}}$ mice. Whole-mount views $(A$ and $B)$ and H\&E-stained histologic sections ( $C$ and $D$ ) of E16.5 and neonatal specimens, respectively. Marked truncation of the antral-pyloric segment of the stomach (brackets) and lack of the pyloric constriction (arrowheads) are readily evident. The spleen (Sp) is also absent or markedly hypoplastic in Bapx 1 cre/cre mice. $(E-H)$ Immunohistochemical analysis of PGP9.5 ( $E$ and $F$ ) and smooth muscle $\alpha$-actin $\left(G\right.$ and $H$ ) in Bapx $1^{\text {cre/cre neonatal }}$ hindstomach indicates ostensibly intact enteric nerve and smooth muscle differentiation, respectively. Arrows point to immunostaining of ganglia ( $E$ and $F$ ) or smooth muscle $(G$ and $H)$. Red bars demarcate the pylorus and highlight the marked difference in width between control and mutant samples.

GFP transgene (Supplementary Figure 4), a marker of the developing spleen. ${ }^{12,25}$

Bap $\times 1^{\text {Cre/Cre }}$ stomachs were modestly reduced in size. Nearly all of this reduction occurred in the distal segment, which was also dilated and lacked constriction at the gastro-duodenal junction, the site of the pyloric sphincter (Figure $3 A$ and $3 B$ ). Histologic examination confirmed distal dilatation and revealed severe shortening of the antral-pyloric segment (Figure $3 C$ and $3 D$ ). Expression and distribution of PGP9.5, an enteric ner- vous system marker, ${ }^{26,27}$ and smooth-muscle $\alpha$-actin were intact (Figure 3E-3H).

Epithelia in the gastric body and antrum have distinctive features. Specialized, Alcian blue-avid mucous cells found at the base of antral gland units are normally absent from the corpus; conversely, the antrum lacks chief and oxyntic cells, the dominant lineages in the body. ${ }^{1}$ Normal hindstomach hence corresponds to the Alcian blue-staining region between the zone of chief and parietal cells in the corpus and the villous duodenal epithelium (Supplementary Figure 5A). Bapx $1^{\mathrm{Cre} / \mathrm{Cre}}$ stomachs carried few, and in many cases, no glandular units with basal Alcian blue avidity (Figure $4 A$ and $4 E$ vs $4 B$ and $4 F$ ), whereas intestinal goblet cells stained readily with Alcian blue (Figure $4 F$ ). Additionally, the distance between $\mathrm{H} / \mathrm{K}$-ATPase- (Figure $4 \mathrm{C}$ and $4 G$ vs $4 D$ and $4 H$ ) or gastric intrinsic factor (Supplementary Figure $5 B-E$ )expressing cells in the stomach body and the villous intestinal epithelium was markedly reduced. These corpus lineage markers frequently abutted the intestine (Figure $4 H$, Supplementary Figure 5E), indicating diminution or loss of mature antral character. Scrutiny of Alcian blue, H/K-ATPase, and gastric intrinsic factor stains revealed normal cell composition in distal corpus glands and absence of mixed corpus-antral units (Supplementary Figure $5 F$ ).

Thus, absence of Bapx1 leads to significant hindstomach truncation and loss of the pyloric constriction. The normal appearance of gastric smooth muscle (Figure $3 \mathrm{H}$ ) and ostensibly normal intestine and gastric corpus point to a localized defect in antral-pyloric development. Although histologic examination sometimes gave the impression that antral hypoplasia was more severe along the lesser than the greater curvature of the stomach (eg, Figure $4 C$ and $4 D$ ), most samples lacked such disparity (eg, Figure $3 C$ and $3 D$, Supplementary Figure $6 B$ ), which we attribute to subtle variation in tissue orientation. Indeed, objective quantitation of multiple samples confirmed that both aspects of the antrum were affected (Supplementary Figure 6A).

\section{Molecular Correlates of Bapx1 in Hindstomach Development}

Indian Hedgehog (Ihb) mRNA is enriched in fetal mouse corpus and antrum, whereas Sonic hedgehog (Shb) is enriched in the forestomach. ${ }^{28}$ In a sign that early patterning is preserved in Bapx $1^{\mathrm{Cr} /} / \mathrm{Cre}$ stomach, the boundaries of $I h b$ (Figure $5 A$ and $5 B$ ) and $S h b$ (data not shown) expression were intact at E11.5. Expression of the homeobox gene $P d x 1$ is normally limited to the antralpyloric segment, providing a reliable marker of this stomach region. ${ }^{29} \mathrm{Pdx} 1$ expression also was similar in Bapx $1^{\mathrm{Cr} / \mathrm{Cre}}$ and wild-type stomach early in development (E11.5 and E14.5 shown in $5 C-5 F$ ). Consistent with the observation of antral hypoplasia, the $P d x 1$ expression domain was substantially smaller at E18.5 (data not shown). However, 


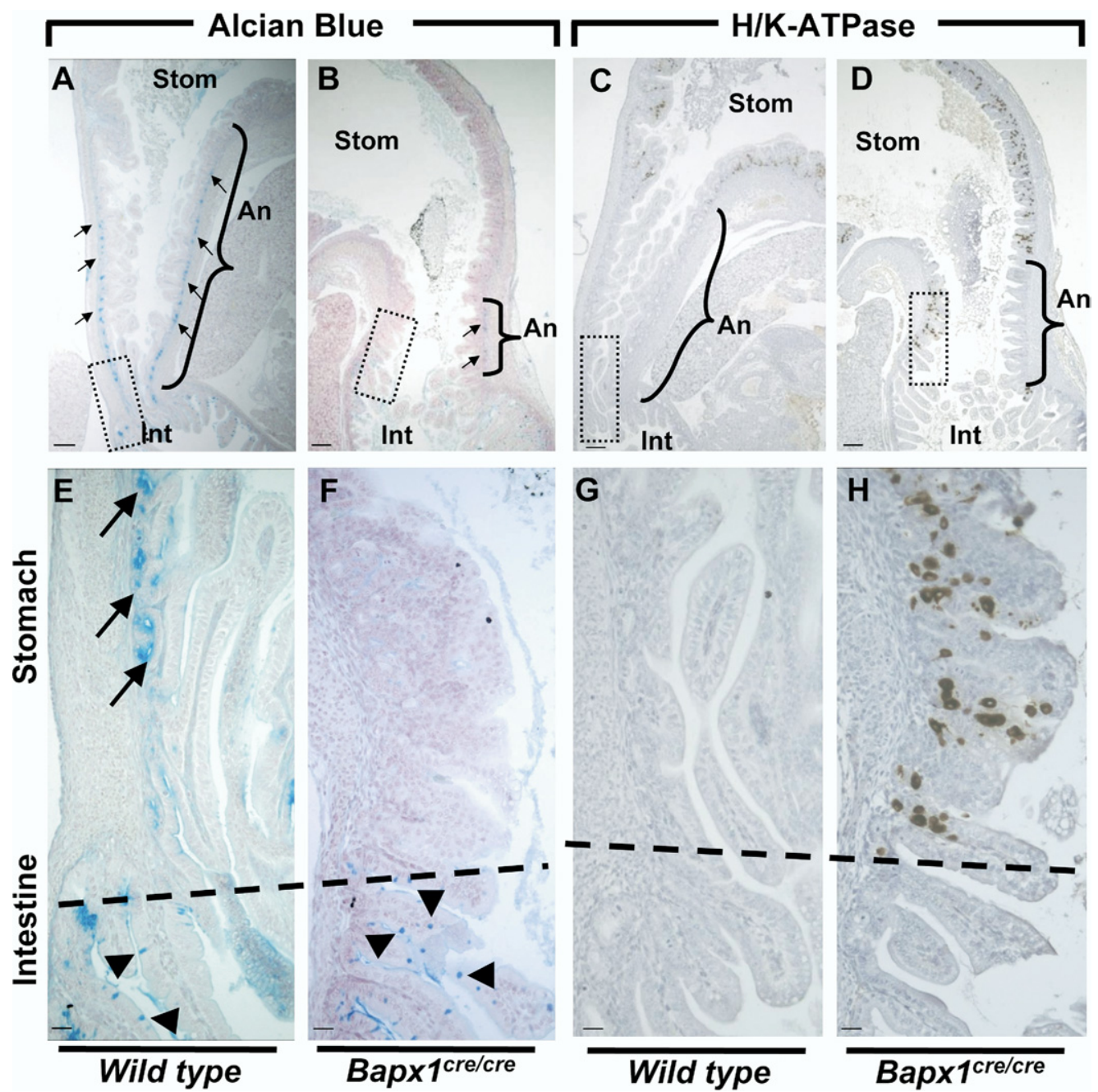

Figure 4. Regional markers verify hindstomach epithelial defects in Bap $\times 1^{\text {Cre/Cre }}$ mice. Critical examination of antral Alcian blue staining and of the gastric corpus marker H/K-ATPase. $(A-D)$ Low-power microscopic views of the gastro-duodenal junction in wild-type $(A$ and $C)$ and Bapx 1 Cre/Cre $(B$ and $D)$ neonates. Brackets mark the region expressing antral-pyloric markers along the greater curvature (An, antrum-pylorus), separating the stomach (stom) corpus from intestine (int). Boxes outline regions of the gastro-duodenal junction shown at higher magnification in panels $E-H$. Alcian blue staining in mutant antral epithelium, which marks characteristic mucous cells at the gland base (arrows) in wild-type mice ( $A$ and $E$ ), is significantly reduced along the greater curvature and missing from the lesser curvature. Intestinal goblet cells (arrowheads), which also stain with Alcian blue, are unaffected. Conversely, H/K-ATPase immunostaining marks parietal cells in wild-type gastric corpus and is absent from normal antral-pyloric

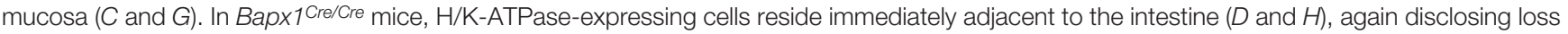
of antral mucosa. Similarly, expression of intrinsic factor, a marker of corpus-resident zymogenic cells, abuts the intestine along the lesser curvature and comes close to the intestine along the greater curvature in Bapx1Cre/Cre stomach (Supplementary Figure 3). Scale bars, A-D, $300 \mu \mathrm{m}$; E-H, $60 \mu \mathrm{m}$.

the typical transition in staining pattern between antrum and corpus, and the symmetry across greater and lesser curvatures, were preserved. Antral hypoplasia in the absence of Bapx1 hence occurs on the background of correct anterior-posterior stomach patterning.

In chick embryos, $N k x 2.5$ and $B a p x 1$ are expressed in the distal stomach (gizzard), whereas Bmp4 and Wnt5a appear in the proximal proventriculus and are excluded from the gizzard. ${ }^{15,30} \mathrm{Nkx} 2.5$ may regulate pyloric sphincter development, and forced Bapx1 expression in the proventriculus inhibits endogenous Bmp4 expression. ${ }^{15}$ In mouse embryos, by contrast, we observed $B m p 4$ expression throughout stomach and intestinal mesenchyme (data not shown); Nkx2.5 mRNA and protein were also expressed widely in mesoderm at the gastroduodenal junction but clearly enriched in pyloric sphincter muscle, as predicted (Figure $5 G$ and Supplementary Figure 2). Levels and distribution of both Nkx2.5 (Figure 5H, Supplementary Figure 4) and Bmp4 (data not shown) were unaltered in Bapx $1^{\mathrm{Cr} / \mathrm{Cre}}$ stomach, indicating that Bapx1 loss does not interfere with their expression.

Next, we surveyed changes in $B a p x 1^{\mathrm{Cr} / / \mathrm{Cre}}$ antral gene expression, using microarray analysis followed by quantitative reverse-transcription polymerase chain reaction (qRT-PCR) confirmation of representative results (data not shown). Because early stomach pattern seems intact, we reasoned that antra from older embryos would better reveal aberrant gene expression. The distal stomach in 


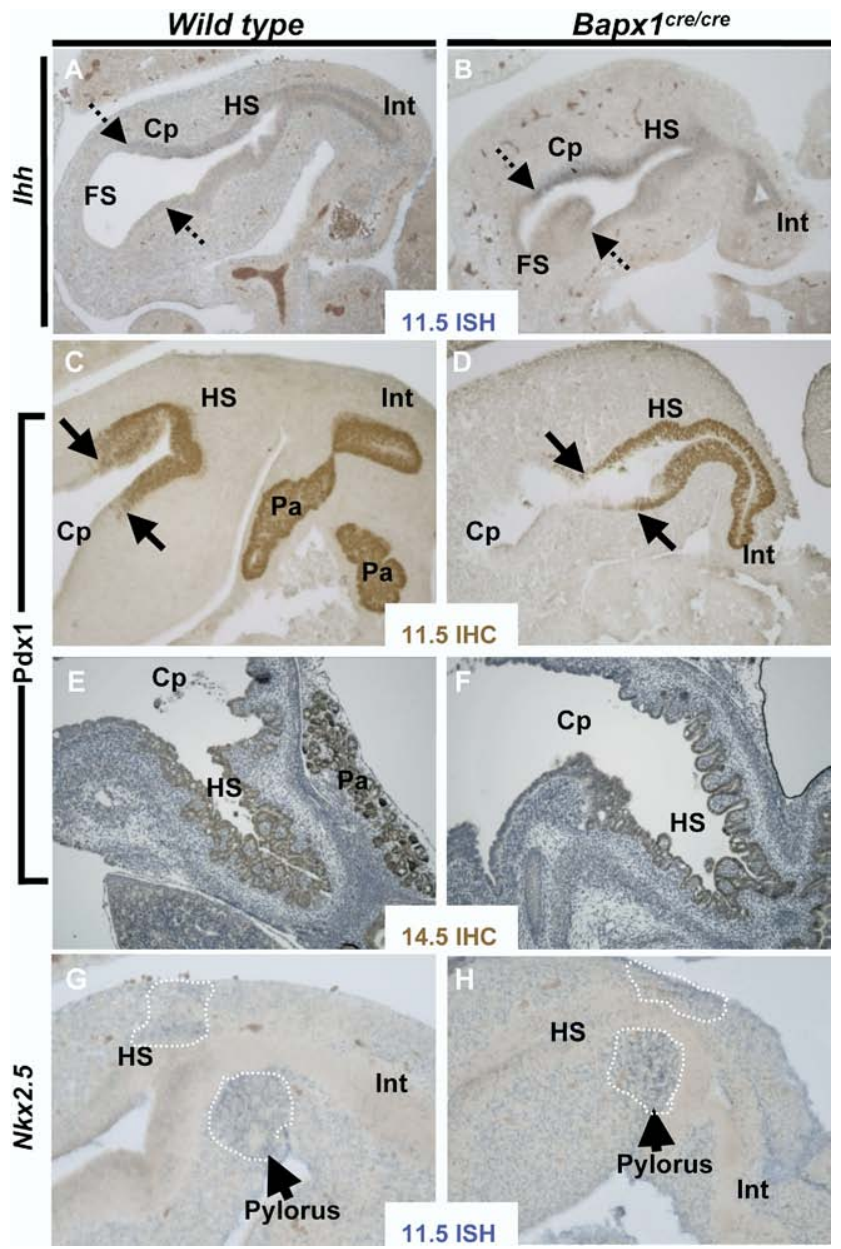

Figure 5. Molecular correlates of embryonic stomach pattern and pylorus development imply normal patterning early in Bapx 1 Cre/Cre stomach development. (A-F) Markers of hindstomach endoderm, Ihh mRNA $(A$ and $B)$, and $\mathrm{Pdx} 1$ protein $(C-F)$, showed no difference in expression between wild-type and Bapx $1^{\text {Cre/Cre }}$ stomachs at E11.5 (A-D) or E14.5 ( $E$ and $F$ ). Dashed arrows mark the rostral limit of Ihh expression, which is much stronger in hindstomach (HS) and corpus $(C p)$ compared with forestomach (FS); solid arrows mark the anterior boundary of PDX1 expression, at the corpus-antral junction. PDX1 is also expressed in proximal intestine (Int) and pancreas $(\mathrm{Pa})$, as seen especially clearly in the control samples $(C$ and $E$ ). ( $G$ and $H$ ) Expression of the chick hindstomach and pyloric determinant Nkx2.5 mRNA in Bapx $1^{\mathrm{Cre} / \mathrm{Cre}}$ and wild-type stomachs at E11.5. Nkx2.5 expression, which marks developing pyloric sphincter muscle (arrows, dashed lines), was unaffected by Bapx1 loss. Similar results were observed by immunostaining (E14.5, data not shown). ISH, in situ hybridization; IHC, immunohistochemistry.

Bapx $1^{\mathrm{Cre} / \mathrm{Cre}}$ embryos at E18.5 showed an increase in corpus-specific $H / K$-ATPase and Gif transcripts and a corresponding decrease in antrum-specific Muc6 mRNA (Supplementary Table 1A). These changes are consistent with the loss of antral, and distal extension of corpus, character. Considering functional gene classes (Gene Ontology), we noted increased expression of transcripts in groups related to epithelial-mesenchymal transition and regulation of endocytosis, whereas groups associated with Smad proteins, nuclear protein import, and vesicle membranes were expressed at lower levels (Supplementary
Table $1 B$ ). These molecular changes in distal Bapx $1^{\mathrm{Cre} / \mathrm{Cre}}$ stomach represent an unknown combination of additional regional markers and possible underpinnings of antral hypoplasia.

\section{Bapx1 May Function Downstream of Barx1 to Mediate Antral-Pyloric Development}

Bapx1 is coexpressed in embryonic hindstomach mesenchyme with Barx1, although the domain of Barx1 expression encompasses nearly the whole stomach (Figure $6 A$ ). Both genes influence differentiation of overlying stomach endoderm and formation of the pyloric sphincter; the antral segment is abbreviated in $\mathrm{Bap} \times 1^{\mathrm{Cre} / \mathrm{Cre}}$ mice (Figures 3 and 4) and likely lost in Barx $1^{-/-}$mice. ${ }^{12} \mathrm{We}$ crossed mice to produce compound homozygote mutants, which we studied immediately after birth because $B a r x 1^{-/-}$mice die of respiratory failure in the perinatal period. ${ }^{12}$ Stomach anomalies in $B a r x 1^{-/-} ; B a p x 1^{\mathrm{Cre} / \mathrm{Cre}}$ and Barx $1^{-/-} ; B a p x 1^{+/+}$neonates were identical (Figure $6 B$ and $6 C$ ); there was no worsening of the isolated Barx1 mutant phenotype, which is more severe than the Bap $x 1^{\text {Cre/Cre }}$ antral defect.

To evaluate further the relationship between these coexpressed factors, we investigated gene expression in each individual knockout strain. Levels and distribution of Barx 1 mRNA were not reduced or altered in fetal Bap $x 1^{\text {Cre/Cre }}$ stomachs and may even increase slightly (Figure $6 D$ and $6 E$, Supplementary Table $1 A$ ). Thus, Barx1 does not require Bapx 1 for its expression and acts either upstream or independent of Bapx1. Conversely, we detected Bapx1 transcripts in wild-type hindstomach and spleen (Figure $6 F$, arrow and arrowhead) but not in the caudal Barx $1^{-/-}$stomach (Figure 6G, arrow), indicating that hindstomach Bapx1 expression requires Barx1 function. Bapx1 expression was equally robust in wild-type and Barx $1^{-/}$somites (Figure 6G, inset), ruling out trivial reasons for lack of a stomach signal. qRT-PCR and immunoblot analyses confirmed that Bapx1 mRNA levels were markedly reduced or absent in $B a r \times 1^{-/-}$stomachs (Figure $6 H$ and 6I). These observations collectively suggest that Bapx1 expression depends on Barx1 and that antral dysmorphogenesis in Barx $1^{-/-}$stomachs might potentially reflect the attendant Bapx1 deficiency.

\section{Discussion}

Organogenesis requires positional cues to specify cell and tissue types correctly. Homeobox genes play a vital role in regulating developmental processes and imparting positional identity. ${ }^{31,32}$ We used homologous recombination to drive Cre expression from the mouse Bapx1 locus, thus creating a new null allele to define expression and study gene function in the developing gut. Bap $x 1^{+/ \text {Cre }} ;$ ROSA26R mice confirmed Bapx1 expression domains reported previously in cartilage and spleen and revealed that, early in digestive tract development, Bapx1-expressing cells and their progeny are confined to 
A

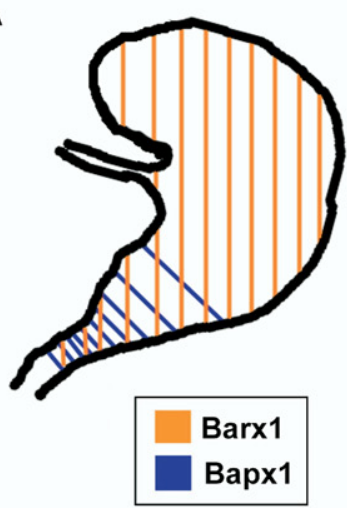

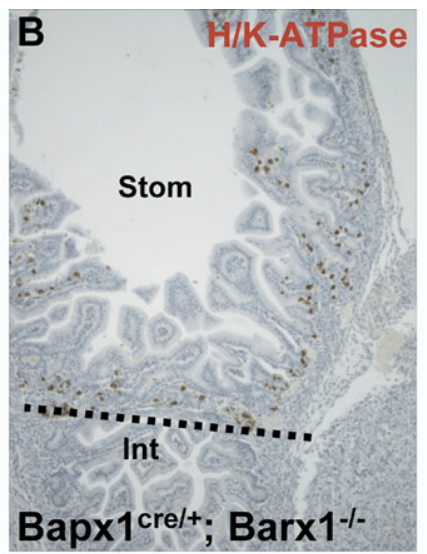
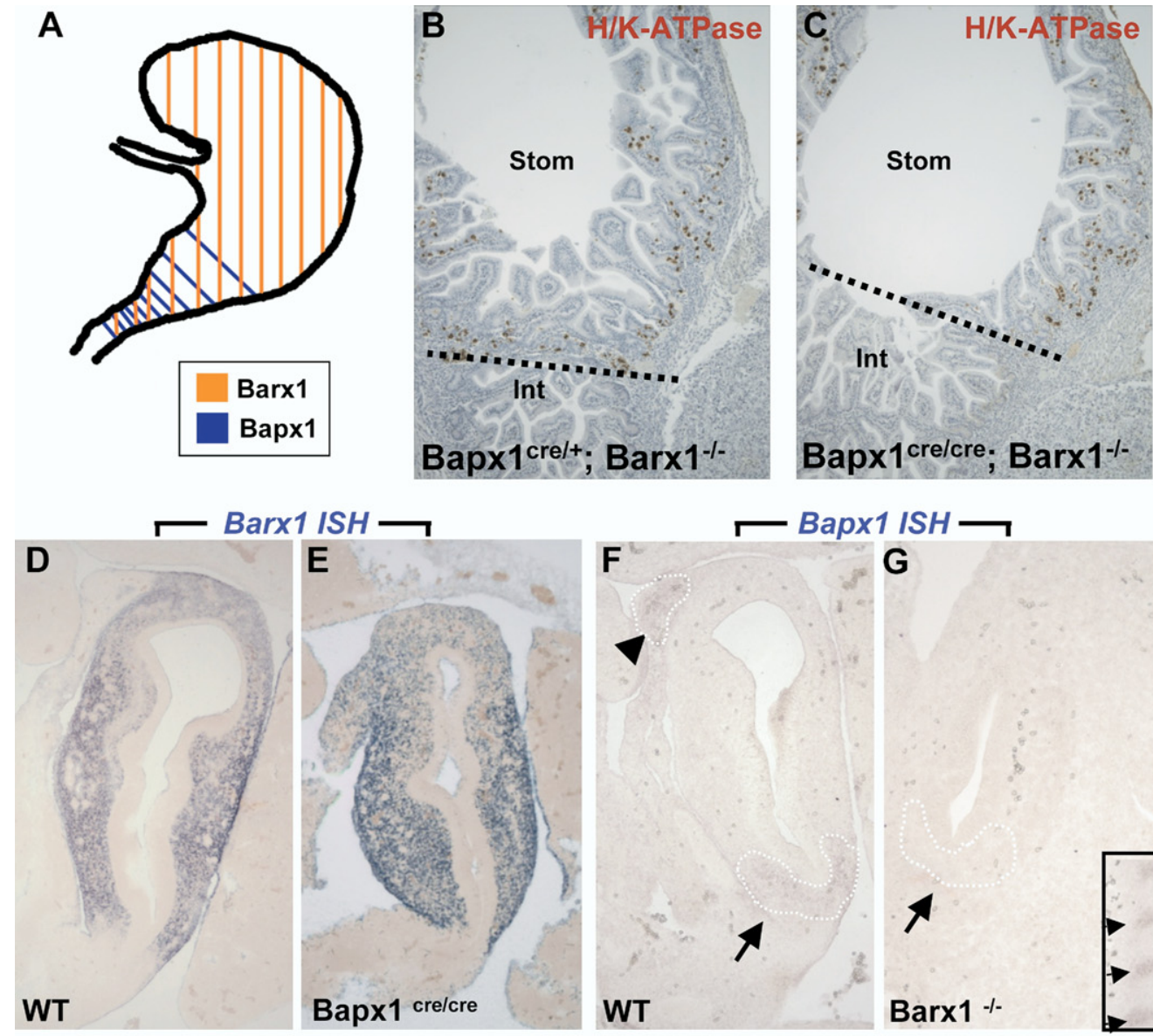

$\mathrm{H}$

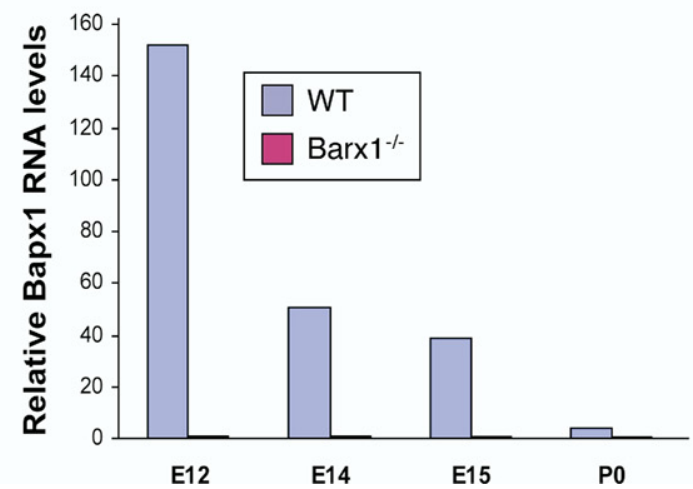

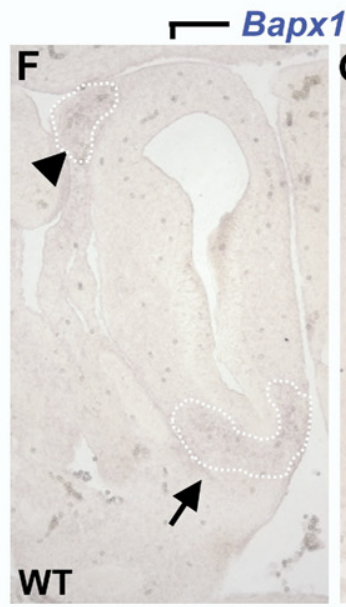

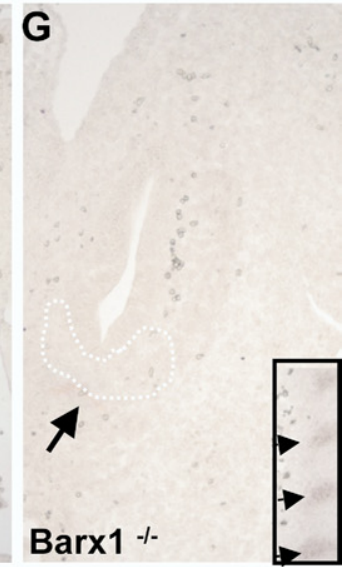

I

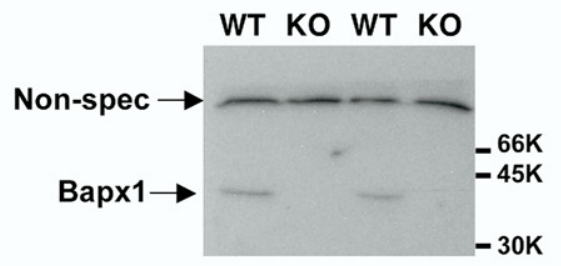

GAPDH

Figure 6. Barx1 may function upstream of Bapx1 to control antral-pyloric development. (A) Schematic depiction of Barx1 and Bapx1 expression in midgestation mouse stomach mesenchyme. Early Bapx1 expression is restricted to the antrum and pylorus (blue) and overlaps with Barx1 expression, which extends throughout the stomach (orange). ( $B$ and $C$ ) Further loss of Bapx1 does not worsen the stomach phenotype in Barx $1^{-1-}$ mice. Stomachs from Barx $1^{-/-} ; \operatorname{Bapx} 1^{\mathrm{Cre} /+}(B)$ and Barx $1^{-/-} ; \operatorname{Bapx} 1^{C r e / C r e}(C)$ neonates are shown. H/K-ATPase immunostaining reveals that a defined parietal cell-depleted region representing the antrum is absent with loss of Barx 1 regardless of whether Bapx 1 is functional or not. Other markers such as Cdx2 and Alcian blue staining gave similar results (data not shown). ( $D-G)$ In situ mRNA analysis confirms the overlapping schema depicted in panel $A$ and reveals an expression hierarchy between Barx1 and Bapx1. Barx1 mRNA, which is expressed throughout fetal stomach mesenchyme, is unaltered in level or distribution with loss of Bapx1 ( $D$ and $E$ ), whereas Bapx1 expression in the embryonic hindstomach is severely compromised with Barx1 loss ( $F$ and $G$; arrows and dashed outlines mark hindstomach mesenchyme). Bapx1 expression was also observed in wild-type spleen ( $F$, arrowhead and dashed outline), but loss of this signal occurred selectively in hindstomach; somites, another prominent site of Bapx1 expression ( $G$ inset, small arrows), were unaffected. ( $H$ and $I)$ Confirmation of loss of Bapx 1 expression by qRT-PCR and immunoblotting. RNA was isolated from stomachs dissected at multiple developmental stages and normalized to Gapdh levels $(H)$, or Bapx1 protein levels were examined in E13.5 stomachs by immunoblot analysis (I). Bapx1 expression was virtually undetectable by either method in Barx $1^{-/-}$stomachs.

the intestine and prospective hindstomach. In line with this observation, Bapx $1^{\text {Cre/Cre }}$ mice show significant shortening of the antral segment and virtual apposition of the gastric body to the duodenum. Pdx1 and Ihh, 2 posterior markers, show correct regional expression, implying that certain elements of early stomach patterning are preserved. Thus, Bapx $1^{\mathrm{Cre} / \mathrm{Cre}}$ hindstomach defects seem to reflect a failure of proper expansion and morphogenesis 
of the antral-pyloric segment. Because the affected region corresponds to that where Bapx1 expression initiates in the digestive tract, we infer that Bapx1 activity is uniquely responsible for these aspects, even if the precise molecular mechanism is presently unknown.

Despite ostensibly normal smooth muscle differentiation and preserved expression of $N k x 2.5$, a gene implicated in chick gizzard development, ${ }^{30}$ Bap $x 1^{\text {Cre/Cre }}$ mice also lack normal pylorus morphology. Mice deleted for nearly the full Hoxd gene cluster lose multiple gastrointestinal valves, including the pyloric sphincter, with associated changes in regional smooth muscle and mucosa $^{9}$; the pyloric constriction is also missing in Barx $1^{-/-}$mice. ${ }^{12}$ These findings may be relevant to hypertrophic pyloric stenosis, a common congenital disorder. ${ }^{33}$ Future efforts should aim to understand how these homeobox genes interact to generate the pyloric sphincter.

The stomach corpus and intestine developed normally, indicating that the antrum-pylorus is the only gut segment that requires Bapx 1 for proper development. Alternatively, Bapx1 may function redundantly with other homeobox genes elsewhere. Less likely, abnormal hindstomach development could reflect dysmorphogenesis of the spleen and pancreas. Around E8.5 in mouse development, Bapx1 mediates lateral growth of the splanchnic mesodermal plate and coupled leftward growth of the dorsal pancreas, associated with control of Fgf10 expression. ${ }^{34}$ However, anomalies akin to those we identify in Bap $x 1^{\text {Cre/Cre }}$ stomach are not seen with a wide range of defects in spleen and pancreas development. ${ }^{12,25}$ In chondrocytes, Bapx1 serves both proliferative and antiapoptotic roles, ${ }^{19,35}$ and one reason the antrum and pylorus may develop aberrantly in its absence is if hindstomach progenitors are disadvantaged relative to anterior cells programmed for corpus differentiation. Immunostaining for cleaved caspase 3 did not reveal excess apoptosis in E11.5 hindstomachs (data not shown).

Forced Bapx1 expression in the chick proventriculus (forestomach) suppresses Bmp4 and Wnt5a expression and region-specific differentiation; conversely, forced expression of Bapx1-VP16, which artificially converts a presumed repressor into a transcriptional activator, promotes occasional expression of BMP4 and Wnt5a in the gizzard. ${ }^{15,36}$ By contrast, Bmp4 expression does not appear to be compartmentalized in the mammalian stomach nor did we detect aberrant expression of Bmp4 or Nkx2.1 in the mutant organ. Thus, despite similarities in Bapx1 expression and function in developing posterior stomach, phenotypes and affected pathways in chick and mouse seem different. These could reflect different mechanisms to create the keratinized avian gizzard vs the glandular mammalian antrum.

Although Barx1 and Bapx1 appear in different compartments in the developing spleen and their mutant phenotypes in that organ are distinct, $12,18,19,21,37$ their expression in distal stomach mesenchyme is overlapping.
Absence of Barx1 markedly disrupts stomach development, producing aberrant morphogenesis, intestinal homeosis, and pyloric sphincter agenesis. Additional loss of Bapx1 does not worsen this phenotype, and the greater severity of antral-pyloric defects in the Barx1 mutant hints at actions upstream of Bapx1. Indeed, Bapx 1 expression is virtually lost in Barx1-null stomach, and its absence could potentially account for some part of the Barx $1^{-/-}$phenotype in the distal organ. Mice with tissuespecific loss of a third stomach transcription factor, the nuclear hormone receptor COUP-TFII, also show a mild patterning defect. ${ }^{38}$ Besides expansion and disorganization of circular smooth muscle and enteric neurons, the margin between forestomach and corpus is shifted anteriorly, and the glandular stomach accordingly occupies a larger relative space. Although expansion of the corpus is a common feature of the 2 phenotypes, they occur at opposite ends: anteriorly in the case of COUP-TFII deficiency and posteriorly in Bapx $1^{\mathrm{Cre} / \mathrm{Cre}}$ animals.

Barx1 is expressed throughout stomach mesenchyme, whereas Bapx1 is initially confined to the caudal region. Thus, although Barx1 seems to be required for stomach Bapx1 expression, it cannot be sufficient to restrict expression to the hindstomach; other factors may promote Bapx1 expression caudally or repress it rostrally. We are presently investigating Barx1's role in COUP-TFII expression. Our results meanwhile implicate Barx 1 and Bapx1 within an essential pathway for mammalian hindstomach development.

\section{Supplementary Data}

Note: To access the supplementary material accompanying this article, visit the online version of Gastroenterology at www.gastrojournal.org, and at doi: 10.1053/j.gastro.2009.01.009.

\section{References}

1. Karam SM, Leblond CP. Identifying and counting epithelial cell types in the "corpus" of the mouse stomach. Anat Rec 1992; 232:231-246.

2. Haffen K, Kedinger M, Simon-Assmann P. Mesenchyme-dependent differentiation of epithelial progenitor cells in the gut. J Pediatr Gastroenterol Nutr 1987;6:14-23.

3. Beck F, Tata F, Chawengsaksophak K. Homeobox genes and gut development. Bioessays 2000;22:431-441.

4. Kawazoe Y, Sekimoto T, Araki M, et al. Region-specific gastrointestinal Hox code during murine embryonal gut development. Dev Growth Differ 2002;44:77-84.

5. Pitera JE, Smith VV, Thorogood P, et al. Coordinated expression of 3' hox genes during murine embryonal gut development: an enteric Hox code. Gastroenterology 1999;117:1339-1351.

6. Wolgemuth DJ, Behringer RR, Mostoller MP, et al. Transgenic mice overexpressing the mouse homoeobox-containing gene Hox1.4 exhibit abnormal gut development. Nature 1989;337:464467.

7. Boulet AM, Capecchi MR. Targeted disruption of hoxc-4 causes esophageal defects and vertebral transformations. Dev Biol 1996; 177:232-249. 
8. Kondo T, Dolle P, Zakany J, et al. Function of posterior HoxD genes in the morphogenesis of the anal sphincter. Development 1996;122:2651-2659.

9. Zakany J, Duboule D. Hox genes and the making of sphincters. Nature 1999;401:761-762.

10. Zacchetti G, Duboule D, Zakany J. Hox gene function in vertebrate gut morphogenesis: the case of the caecum. Development 2007; 134:3967-3973.

11. Kim BM, Buchner G, Miletich I, et al. The stomach mesenchymal transcription factor Barx1 specifies gastric epithelial identity through inhibition of transient Wnt signaling. Dev Cell 2005;8: 611-622.

12. Kim BM, Miletich I, Mao J, et al. Independent functions and mechanisms for homeobox gene Barx1 in patterning mouse stomach and spleen. Development 2007;134:3603-3613.

13. Tissier-Seta JP, Mucchielli ML, Mark M, et al. Barx1, a new mouse homeodomain transcription factor expressed in craniofacial ectomesenchyme and the stomach. Mech Dev 1995;51: 3-15.

14. Smith DM, Tabin CJ. BMP signalling specifies the pyloric sphincter. Nature 1999;402:748-749.

15. Nielsen C, Murtaugh LC, Chyung JC, et al. Gizzard formation and the role of Bapx1. Dev Biol 2001;231:164-174.

16. Azpiazu N, Frasch M. Tinman and bagpipe: two homeobox genes that determine cell fates in the dorsal mesoderm of Drosophila. Genes Dev 1993;7:1325-1340.

17. Tribioli C, Frasch M, Lufkin T. Bapx1: an evolutionary conserved homologue of the Drosophila bagpipe homeobox gene is expressed in splanchnic mesoderm and the embryonic skeleton. Mech Dev 1997;65:145-162.

18. Lettice LA, Purdie LA, Carlson GJ, et al. The mouse bagpipe gene controls development of axial skeleton, skull, and spleen. Proc Natl Acad Sci U S A 1999:96:9695-9700.

19. Tribioli $C$, Lufkin $T$. The murine Bapx1 homeobox gene plays a critical role in embryonic development of the axial skeleton and spleen. Development 1999;126:5699-5711.

20. Akazawa H, Komuro I, Sugitani $\mathrm{Y}$, et al. Targeted disruption of the homeobox transcription factor Bapx1 results in lethal skeletal dysplasia with asplenia and gastroduodenal malformation. Genes Cells 2000;5:499-513.

21. Asayesh A, Sharpe J, Watson RP, et al. Spleen versus pancreas: strict control of organ interrelationship revealed by analyses of Bapx1 $1^{-/-}$mice. Genes Dev 2006;20:2208-2213.

22. Hogan B, Beddington R, Costantini $F$, et al. Manipulating the mouse embryo: a laboratory manual. Cold Spring Harbor, NY: Cold Spring Harbor Laboratory Press, 1994.

23. Chi X, Zhang SX, Yu W, et al. Expression of Nkx2-5-GFP bacterial artificial chromosome transgenic mice closely resembles endogenous Nkx2-5 gene activity. Genesis 2003;35:220-226.

24. Soriano P. Generalized lacZ expression with the ROSA26 Cre reporter strain. Nat Genet 1999;21:70-71.

25. Brendolan A, Ferretti E, Salsi V, et al. A Pbx1-dependent genetic and transcriptional network regulates spleen ontogeny. Development 2005;132:3113-3126.

26. Sams VR, Bobrow LG, Happerfield L, et al. Evaluation of PGP9.5 in the diagnosis of Hirschsprung's disease. J Pathol 1992;168: 55-58.

27. Wilkinson KD, Lee KM, Deshpande S, et al. The neuron-specific protein PGP 9.5 is a ubiquitin carboxyl-terminal hydrolase. Science 1989;246:670-673.

28. Bitgood MJ, McMahon AP. Hedgehog and Bmp genes are coexpressed at many diverse sites of cell-cell interaction in the mouse embryo. Dev Biol 1995;172:126-138.
29. Offield MF, Jetton TL, Labosky PA, et al. PDX-1 is required for pancreatic outgrowth and differentiation of the rostral duodenum. Development 1996;122:983-995.

30. Smith DM, Nielsen C, Tabin CJ, et al. Roles of BMP signaling and Nkx2.5 in patterning at the chick midgut-foregut boundary. Development 2000;127:3671-3681.

31. Wellik DM. Hox patterning of the vertebrate axial skeleton. Dev Dyn 2007;236:2454-2463.

32. Lewis EB. A gene complex controlling segmentation in Drosophila. Nature 1978;276:565-570.

33. De Felice C, Di Maggio G, Toti $P$, et al. Infantile hypertrophic pyloric stenosis and asymptomatic joint hypermobility. J Pediatr 2001;138:596-598.

34. Hecksher-Sorensen J, Watson RP, Lettice LA, et al. The splanchnic mesodermal plate directs spleen and pancreatic laterality and is regulated by Bapx1/Nkx3.2. Development 2004;131:46654675.

35. Park M, Yong $\mathrm{Y}$, Choi SW, et al. Constitutive RelA activation mediated by Nkx3.2 controls chondrocyte viability. Nat Cell Biol 2007;9:287-298.

36. Listyorini D, Yasugi S. Expression and function of Wnt5a in the development of the glandular stomach in the chicken embryo. Dev Growth Differ 2006;48:243-252.

37. Pabst $\mathrm{O}$, Zweigerdt $\mathrm{R}$, Arnold $\mathrm{HH}$. Targeted disruption of the homeobox transcription factor Nkx2-3 in mice results in postnata lethality and abnormal development of small intestine and spleen. Development 1999;126:2215-2225.

38. Takamoto N, You LR, Moses K, et al. COUP-TFII is essential for radial and anteroposterior patterning of the stomach. Development 2005;132:2179-2189.

Received May 22, 2008. Accepted January 8, 2009.

\section{Reprint requests}

Address requests for reprints to: Warren E. Zimmer, PhD, Texas A\&M Health Science, 310B Joe H. Reynolds BIdg, College Station, Texas 77843. e-mail: wezimmer@medicine.tamhsc.edu; fax: (979) 862-4638 or Ramesh A. Shivdasani, MD, PhD, Center Dana-Farber Cancer Institute, 44 Binney Street, Boston, Massachusetts 02115. e-mail: ramesh_shivdasani@dfci.harvard.edu; fax: (617) 582-8490.

\section{Acknowledgments}

The authors thank Renee Braun and Wei Yu for expert technical assistance; Xuan Chi for Nkx2.5-GFP transgenic mice; and D. Alpers, C. Wright, T. Lufkin, A. McMahon, and R. Harvey for antibodies and probes.

M.P.V. and M.N.S. contributed equally to this paper.

\section{Conflicts of interest}

The authors disclose no conflicts.

\section{Funding}

Supported by the National Institutes of Health grants P01HL49953 and P01HL067155 (to R.J.S.), R01CA095608 (to W.E.Z.), R01DK061139 (to R.A.S.); the Center for Environmental and Rural Health, Texas A\&M, P30 ES09106 (to W.E.Z. and R.J.S.); Molecular Endocrinology Training Program grant T32DK07696 (to M.N.S.); training grant T32DK07477 and a fellowship from the Crohn's and Colitis Foundation of America (to M.P.V.); and UNCF/ Merck Graduate Fellowship Program and Robert C. McNair Foundation (to K.A.M.). 